\title{
Characterization of moisture mobility and diffusion in fresh tobacco leaves during drying by the TG-NMR analysis
}

\author{
Gao-fei Guo ${ }^{1} \cdot$ Bin $\mathrm{Li}^{1} \cdot$ Chao-xian $\mathrm{Liu}^{1} \cdot{\mathrm{Xin} \mathrm{Jin}^{2} \cdot \text { Zhao-gai Wang }^{3} \cdot \text { Mei-zhou Ding }}^{4} \cdot$ Liang-yuan Chen $^{1} \cdot$ \\ Ming-jian Zhang ${ }^{1} \cdot$ Wen-kui Zhu' ${ }^{1} \cdot$ Li-feng Han $^{4}$
}

Received: 17 January 2018 / Accepted: 16 April 2018/Published online: 8 May 2018

(C) The Author(s) 2018

\begin{abstract}
Curing is an essential procedure in tobacco primary processing. The moisture mobility and diffusion characteristics during drying are the key factors that affect the curing condition optimization. In the present study, the thermogravimetric analysis (TG) was integrated to the online nuclear magnetic resonance analysis (NMR) to investigate the drying characteristics of fresh tobacco leaves (FTL) during hot air drying at 50 and $60{ }^{\circ} \mathrm{C}$. The results of TG were used to analyze the drying kinetics and obtain the effective diffusion coefficient of moisture of FTL during drying. The moisture diffusion coefficient of FTL was $4.1782 \mathrm{E}-09 \mathrm{~m}^{2} \mathrm{~s}^{-1}$ at $50{ }^{\circ} \mathrm{C}$ and $5.7777 \mathrm{E}-09 \mathrm{~m}^{2} \mathrm{~s}^{-1}$ at $60{ }^{\circ} \mathrm{C}$, respectively. The moisture mobility of the samples at different drying stages was monitored by the NMR analyzer. $T_{2}$ spectra showed that the initial ratios of semibound water and bound water in FTL were 93.2 and $6.8 \%$, respectively. The drying rate showed a decreasing trend with the reduction in relaxation time of $T_{22}$ peak from about $80 \mathrm{~ms}$ to about $30 \mathrm{~ms}$, especially for the ones dried at $60{ }^{\circ} \mathrm{C}$. The reduced relaxation time of $T_{22}$ peak indicated that water activity in FTL was weakened during drying. Moisture distribution obtained by magnetic resonance imaging in FTL at different drying stages can reveal the moisture transfer path.
\end{abstract}

Keywords Fresh tobacco curing · Drying · Low-field nuclear magnetic resonance $\cdot$ TG-NMR/MRI

\section{Introduction}

In tobacco primary processing, fresh tobacco curing after harvesting, an important drying operation unit, could convert tobacco leaves from agricultural products into tobacco industry materials. The quality and flavor of flue-cured tobacco products were influenced significantly by curing technology and conditions [1-3]. For the curing of different kinds of tobacco leaves, it is necessary to choose the

Wen-kui Zhu

wkzhu79@163.com

$\triangle$ Li-feng Han

hanlife@qq.com

1 Zhengzhou Tobacco Research Institute of CNTC, Zhengzhou, China

2 Soochow University, Suzhou, China

3 Institute of Agricultural Products Processing, Henan Academy of Agricultural Sciences, Zhengzhou, China

4 China Tobacco Henan Industrial Co., Ltd, Zhengzhou, China suitable curing technology according to their drying characteristics. On the other hand, when fresh tobacco leaves (FTL) were cured from the initial moisture content of $80-85 \%$ to the final moisture content of $16-18 \%$, the curing conditions of FTL during curing processing also need to be adjusted according to the drying characteristics [4] and thermal properties [5] of materials at different drying stages. At present, the detection and analysis of tobacco drying characteristics mainly used the thermogravimetric analysis (TG) or other laboratory-scale dryer [6] to obtain the drying curves. TG can be employed at isothermal, lowtemperature condition, which simulates the process of fresh tobacco curing to investigate the drying mechanisms. Some drying kinetics parameters, such as the drying rate constant, the moisture diffusion coefficient and the activation energy, can be obtained from TG drying curves [7, 8]. As a non-uniform and porous media, the drying kinetic behavior of FTL during drying is closely related to the internal moisture mobility and diffusion in materials. However, the drying kinetics parameters obtained by TG analysis could only reflect the apparent drying rate. The change in internal 
moisture mobility and distribution in green tobacco leaves during drying is still unknown by the present TG method.

Nuclear magnetic resonance (NMR) technique is based on the atomic nucleus magnetic properties, which provides the transverse relaxation time $\left(T_{2}\right)$ (referred to as spin-spin proton time) to reflect the information on water in various molecular structure, and water within different chemicals or physical environment, etc. [9]. This analysis can easily distinguish the differences between different physical and chemical bindings in water molecules by $T_{2}$ information [10], which can be used as a mean to predict the moisture content and evaluate the water activity. Low-field ${ }^{1} \mathrm{H}$ NMR technology is extensively used by researchers due to its advantages of low-cost, highly inhomogeneous magnetic fields without the limitations of enclosing the sample in multitudinous coils and shields [11]. In recent years, ${ }^{1} \mathrm{H}$ NMR is applied into the determination of the moisture content [12], moisture diffusion [13-15], moisture distribution [16-20], water activity [9, 21, 22], oxidative stability of oil [23] and other properties of agricultural products. In addition, it is also used to study the protons from organic functional groups of compounds [24, 25] and the compositions of the soil organic matter [26]. In particular, magnetic resonance imaging technique (MRI) is a form of NMR. It can produce two- or three-dimensional images by recording proton spin-spin relaxation times, which can help to understand the transport process and visualize the spatial moisture distribution and inner structures of plants [27]. Visualizing the inner moisture distribution of materials by MRI has been intensively investigated [28-34]. Hence, MRI can be applied to intuitively obtain the internal water migration law of raw tobacco materials during drying.

Considering the unique characteristics of NMR, it could be combined with the TG technique to provide further details of drying characteristics, not only on the drying kinetic behavior but also on the water mobility and its distribution in tobacco materials during the drying process. In this work, we present an application of the analytical method combining the TG and ${ }^{1} \mathrm{H}$ NMR to study the drying characteristics of FTL. The objective of this study is to reveal the change in moisture mobility and distribution, and gain a comprehensive understanding on the moisture transport phenomena of FTL during drying. NMR can be applied into tobacco industry as a new method for measuring the moisture content or moisture distribution in tobacco products. In the meantime, it can be used to clarify the effect of different drying conditions on water activity and moisture distribution in FTL during the drying process, which provides a reference for low-field NMR technology applied to tobacco processing. Fundamental applications of NMR in tobacco drying process are actively explored, which is favorable for development of more advanced and efficient technology of fresh tobacco curing.

\section{Materials and methods}

\section{Experimental samples}

The FTL were picked from the green house in Zhengzhou Tobacco Research Institute of CNTC. As shown in Fig. 1, FTL with the initial moisture content of 78-83\% were cut into tobacco strips with the size of $15 * 15 \mathrm{~mm}$. Then approximate $2 \mathrm{~g}$ samples were put into the sample pan and inserted to the TG-NMR analyzer.

\section{Experimental apparatus}

TG was integrated into an NMR analyzer (Suzhou Niumag analytical instruments Co., Ltd., Suzhou, China). In the joint analyzer, the sample pan located in the magnets cabinet of low-filed NMR analyzer was hung under the high-precision electric balance (Sartorius Scientific Instruments Co., Ltd., Germany). The sample located in sample pan was dried by hot air with a constant temperature. In the test, the mass changes were measured by the electric balance, and the transverse relaxation time of sample was received by the NMR system. The data of TG and NMR were recorded in situ by the computer simultaneously after the start of the testing. The apparatus consisted of three parts: TG test part, hot air supplier and online NMR test part. The hot air temperature could be adjusted by a temperature controller from 50 to $90{ }^{\circ} \mathrm{C}$ with the accuracy of $\pm 1{ }^{\circ} \mathrm{C}$. The online NMR test part performed proton relaxation measurements with an NMR analyzer equipped a $0.5 \mathrm{~T}$ permanent magnet, which was operated at a frequency of $23 \mathrm{MHz}$.

\section{Drying and NMR experiment}

Taking into account the fresh tobacco-curing technology and NMR maximum operating temperature, a continuous flow controlled at 50 and $60{ }^{\circ} \mathrm{C}$ was supplied, respectively. The air velocity was approximately $0.5 \mathrm{~m} / \mathrm{s}$. The drying and NMR experiment consisted of offline NMR test part and online NMR test part. In the online part, 13 pieces of FTL with size of $15 * 15 \mathrm{~mm}$, about $8 \mathrm{~mm}$ thickness, were taken into the sample pan of TG-NMR analyzer with hot air temperature controlled at 50 and $60{ }^{\circ} \mathrm{C}$, respectively. In the present work, mass and $T_{2}$ were detected by the drying time interval of 1 and $10 \mathrm{~min}$, respectively. The MRI measurement was taken with the time interval of $60 \mathrm{~min}$. In the offline part, the FTL dried for 5, 10, 20, 30, 40, 50, $60,70,80,90,100 \mathrm{~min}$, even longer time, were fetched out 


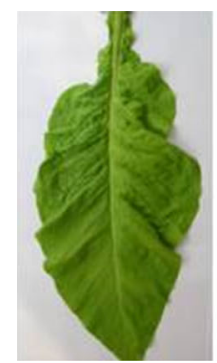

Fresh tobacco leaf

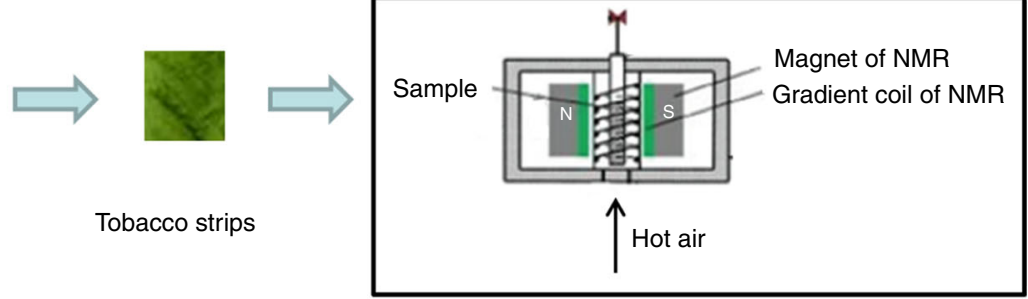

Sample tube of TG-NMR analyzer

Fig. 1 Preparation process for raw tobacco sample

from the blast oven and then were sent to sample pan of TG-NMR analyzer for test at once.

During the testing process, sample mass was measured by TG to obtain the drying curves (moisture content VS. drying time). The calculation method of moisture ratio $(M R)$ was shown in the following equation:

$\mathrm{MR}=\frac{M-M_{\mathrm{eq}}}{M_{0}-M_{\mathrm{eq}}}$

where MR, the moisture ratio, is the dimensionless moisture content; $M$ is the mean moisture content in dry basis of the material at time $t, \% ; M_{\text {eq }}$ and $M_{0}$, respectively, represent the equilibrium and initial moisture contents in dry basis, \%. As shown in Fig. 2, the results of $M R$ should be smoothed. Meanwhile, radiofrequency signal was launched and received by NMR to obtain the $T_{2}$ spectra of samples. The $T_{2}$ spectra, as referred to the spin-spin relaxation times of proton in the plant-matrix, could indicate the information of water state and mobility in FTL. According to the proton signal density, MRI analysis could obtain the water spatial distribution in materials. In whole experiment, three replicates of each drying trial were accomplished. $T_{2}$ can be measured by Carr-Purcell-Meiboom-Gill (CPMG) sequence $[35,36]$. In this work, the CPMG sequence was briefly annotated by $90^{\circ}-\left(\tau-180^{\circ}-\tau\right)_{\mathrm{n}}$ and consisted of a $90^{\circ}$ pulse for $15.5 \mu \mathrm{s}$, followed by $\mathrm{n}$ repeated $180^{\circ}$ pulses for $32.5 \mu \mathrm{s}$, at a pulse spacing value $(2 \tau)$ of $1000 \mu \mathrm{s}$. The number of echoes and scan was 1000 and 128, respectively.

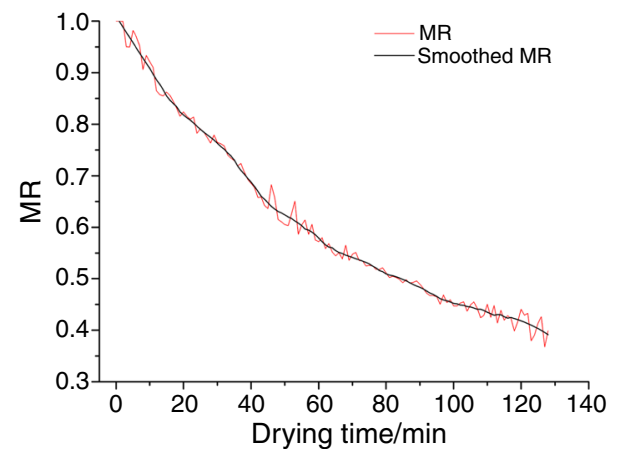

Fig. 2 Smoothed drying curves by TG
The time between each scan (recycle delay) was $500 \mathrm{~ms}$, which allows the magnetization to return to equilibrium. As can be seen from Fig. 3a, the process of signal inversion from the radiofrequency signal strength to the $T_{2}$ spectra can be achieved through the following models [37]:

$I_{\mathrm{CPMG}}(t)=\sum_{\mathrm{i}} I_{\mathrm{i}} \exp \left(-\frac{t}{T_{2 \mathrm{i}}}\right)$

where $t$ is time of the $90^{\circ}$ pulse echo, $T_{2 \mathrm{i}}$ is the spin-spin relaxation time of the mobile populations $i, I_{\mathrm{i}}$ is the population intensity of the component phase $i, I_{\mathrm{CPMG}}$ is the intensity of the materials with CPMG pulse. The curves were then deconvoluted to Gaussian functions (each population being represented by a Gaussian) for a better schematic representation of the $T_{2}$ spectra. In general, the relaxation time of complex systems displayed multi-component behavior, in which each component can be interpreted as representing different water mobility [10]. The proton density map of materials during drying was processed by using MATLAB software to get a pseudo-color image shown in Fig. 3b, which exhibited the internal moisture distribution of FTL at different drying moments.

\section{Mathematics model of moisture diffusion}

Fick's second law of diffusion [Eq. (3)] was used to model the moisture transport during drying, in which the effective diffusion coefficient was assumed to be constant.

$\frac{\partial M}{\partial t}=D_{\mathrm{e}}\left(\frac{\partial^{2} M}{\partial x^{2}}+\frac{\partial^{2} M}{\partial y^{2}}+\frac{\partial^{2} M}{\partial z^{2}}\right)$

Tobacco strips as a one-dimensional slab material, assuming that the resistance to moisture flow was uniformly distributed throughout the interior of the homogeneous isotropic material. Furthermore, the shrinkage was assumed to be negligible; we could consider that the moisture diffusion was in agreement with the one-dimensional diffusion model [38, 39]. Fick's second law could be reduced simply as follows: 


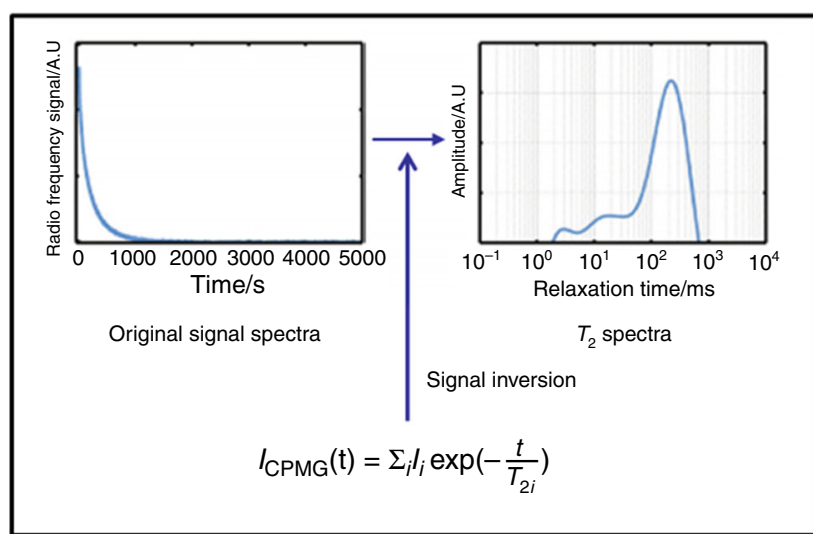

(a)

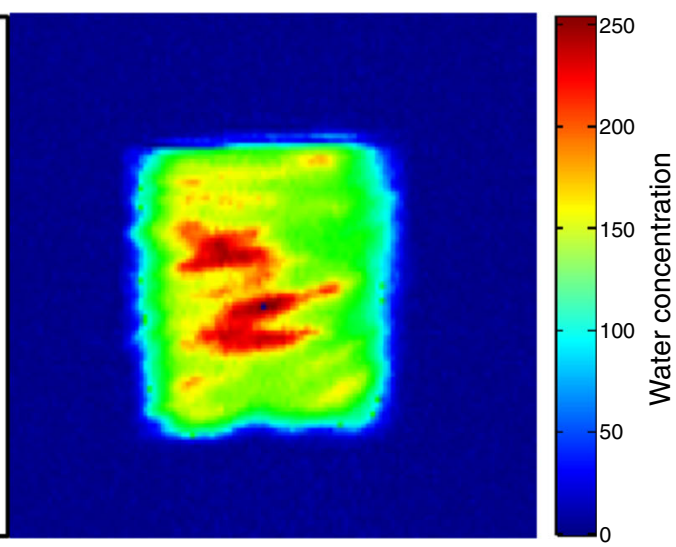

(b)

Fig. $3 T_{2}$ spectra (a), magnetic resonance images (b) by NMR

$$
\frac{\partial M}{\partial t}=D_{\mathrm{e}} \frac{\partial^{2} M}{\partial x^{2}}
$$

where $M$ is the moisture content of the materials, $\% ; x$ is the width of tobacco strips, $\mathrm{m}$; $t$ is the drying time, $\mathrm{s}$; and $D_{\mathrm{e}}$ is the effective diffusion coefficient, $\mathrm{m}^{2} \mathrm{~s}^{-1}$.

For an infinite slab with the spatial uniform moisture distribution and negligible external mass transfer resistance, the solution of one-dimensional Fick's second law [Eq. (4)] has the form [40]:

$\frac{M-M_{\mathrm{eq}}}{M_{0}-M_{\mathrm{eq}}}=\frac{8}{\pi^{2}} \sum_{n=0}^{\infty} \frac{1}{(2 n+1)^{2}} \exp \left[-\frac{(2 n+1)^{2} \pi^{2} D_{\mathrm{e}} t}{(L / 2)^{2}}\right]$

where $M$ is the mean moisture content in dry basis of the material at time $t, \% ; M_{\mathrm{eq}}$ and $M_{0}$, respectively, represent the equilibrium and initial moisture contents in dry basis, $\% ; n$, a dimensionless value, is the order of the equation, while $L$ is the width of test tobacco strips, $m$.

\section{Results and discussion}

\section{Analysis of drying kinetics by TG during drying}

As shown in Fig. 4a, the moisture ratio of FTL dried at $60{ }^{\circ} \mathrm{C}$ was obviously lower than the materials dried at $50{ }^{\circ} \mathrm{C}$. The results were in good agreement with the phenomenon that moisture was more easily dissipated from the material with higher drying temperature. It should be pointed out that the drying curve of tobacco leaves showed a large fluctuation under the drying condition of $60^{\circ} \mathrm{C}$. This may be attributed to the fact that large amounts of water vapor escaping from the matrix which may influence on the stability of the high-precision balance at more intense drying condition. Notably, the tendency of dying curve could basically reflect the drying law of FTL. According to the drying rate profile, the drying process of FTL at 50 and $60{ }^{\circ} \mathrm{C}$ should be divided into Zone I and Zone II as shown in Fig. 4b. As can be seen form part b of Fig. 5, the drying curves of sliced materials at low air temperature $\left(50{ }^{\circ} \mathrm{C}\right)$ included the constant-rate drying stage (0-60 $\mathrm{min}$ ) and the falling-rate drying stage (60-140 min). However, the constant-rate drying stage did not exist in the ones dried at $60{ }^{\circ} \mathrm{C}$. A possible explanation is that the hardened shell was formed on the surface of tobacco leaves under the drying condition of $60{ }^{\circ} \mathrm{C}$ so that the diffusion of water from inside to outside was gradually hindered [3, 41]. Therefore, the initial drying rate showed a steep falling gradient, likely due to the resistance of hardened shell and the shrinkage of interior pores. The falling-rate drying stage at the higher air temperature consisted of the first falling-rate drying stage (0-60 min, the stage of sharp reduction in drying rate) and the second falling-rate drying stage (60-130 min, the stage of slow reduction in drying rate). The results were consistent with the results of Fig. 4a, b.

According to the hypothesis of one-dimensional diffusion of thin materials during drying, the moisture effective diffusion coefficient of FTL could be calculated by Fick's second law. In the experiment, the dehumidified air was used as the drying medium. Under this condition, the tobacco slices were dried until $M_{\text {eq }}$ was very small. Hence, the final equilibrium moisture content could be approximated as zero (lower than the minimum detectable moisture content). For the longer drying process, $n$, which is the order of the equation, was taken as 2 because the higher order could be ignored. Thus, the values of the effective diffusion coefficients were determined by minimizing the sum of squared error between predicted and experimentally measured values of dry basis moisture content. The results 


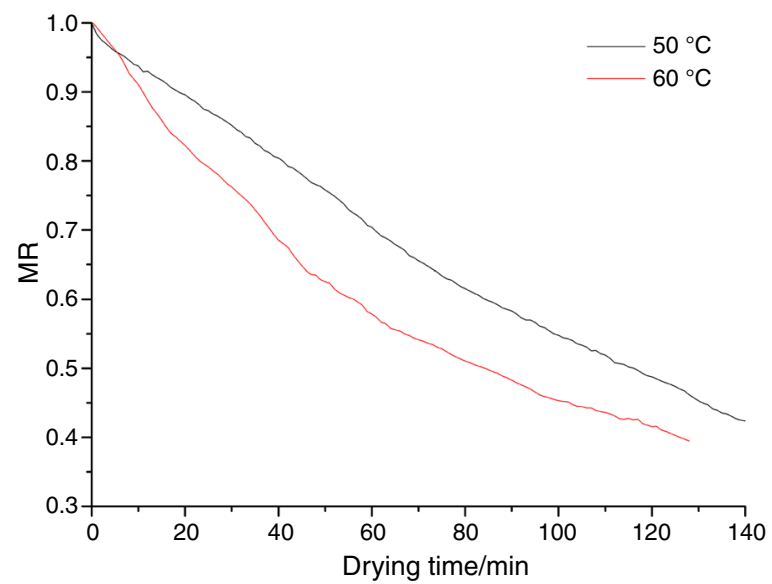

(a)

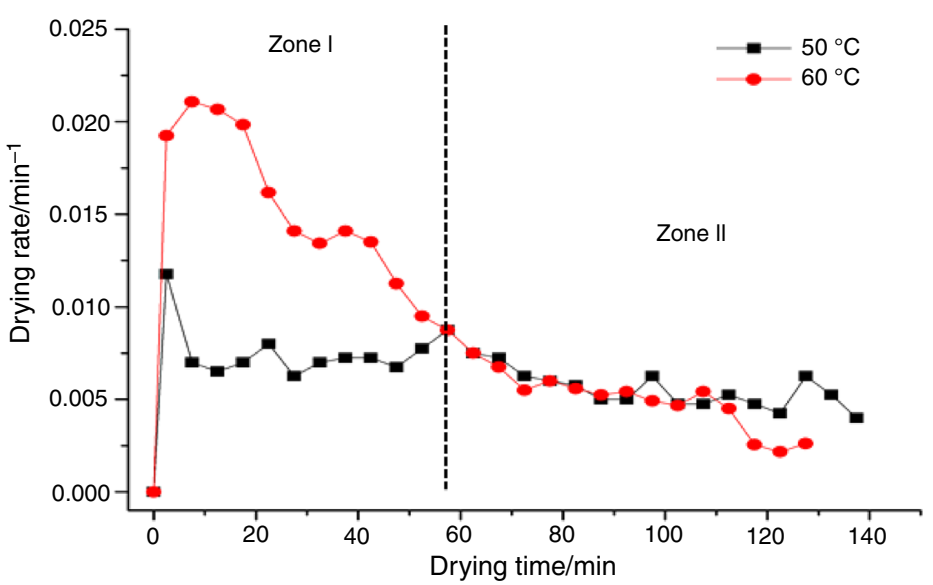

(b)

Fig. 4 Results of drying curves (a), drying rate curves (b) of FTL

(a)

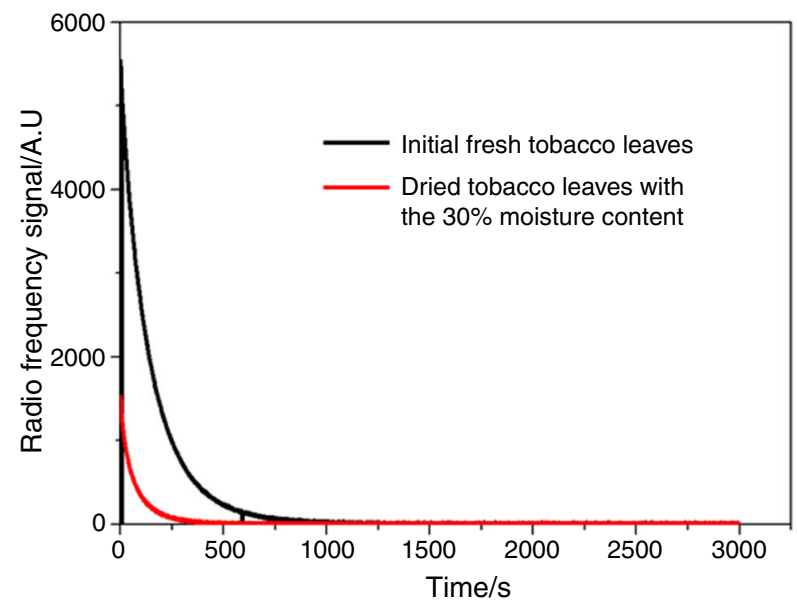

(b)

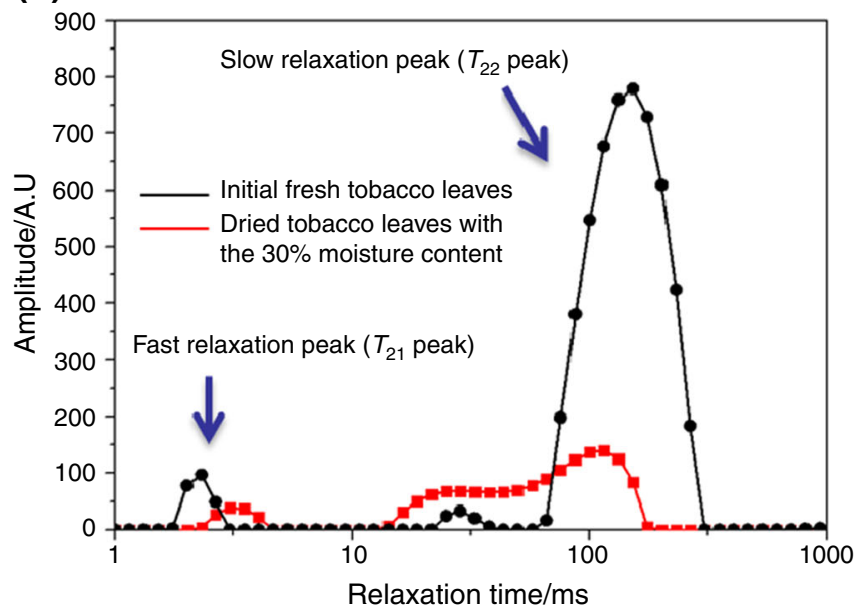

Fig. 5 Signal inversion of NMR of tobacco materials: original signal spectra (a), $T_{2}$ spectra (b)

Table 1 Correlation coefficient and corresponding effective diffusion coefficient of FTL

\begin{tabular}{lll}
\hline Drying temperature $/{ }^{\circ} \mathrm{C}$ & Moisture effective diffusivity $/ \mathrm{m}^{2} \mathrm{~s}^{-1}$ & $R^{2}$ \\
\hline 50 & $4.1782 \mathrm{E}-09$ & 0.9235 \\
60 & $5.7777 \mathrm{E}-09$ & 0.9186 \\
\hline
\end{tabular}

important criterion for distinguishing between bound water and semi-bound water in the FTL, was reflected by $T_{2}$. Notably, the free water and adsorption water were contained in semi-bound water mentioned herein. The peak strength could provide the information on the ratio of bound water and semi-bound water. Table 2 displays the results of relaxation time, relaxation peak strength and water state of FTL. The ratio of semi-bound water and bound water in FTL was 93.2 and $6.8 \%$, respectively, which could be calculated by relaxation peak strength in $T_{2}$ spectra. The relationship between drying time and radiofrequency signal strength in Fig. 5a has confirmed the
NMR was applied to investigate the water mobility and distribution of FTL during drying. Water activity, an 
Table 2 Characteristics of relaxation peak of FTL

\begin{tabular}{lcccl}
\hline Relaxation peak & Relaxation time/ms & Peak strength & Ratio/\% & The corresponding water state \\
\hline$T_{21}$ peak & 3.5119 & 6976.06 & 6.8 & Bound water \\
$T_{22}$ peak & 75.6463 & $95,154.90$ & 93.2 & Semi-bound water \\
\hline
\end{tabular}
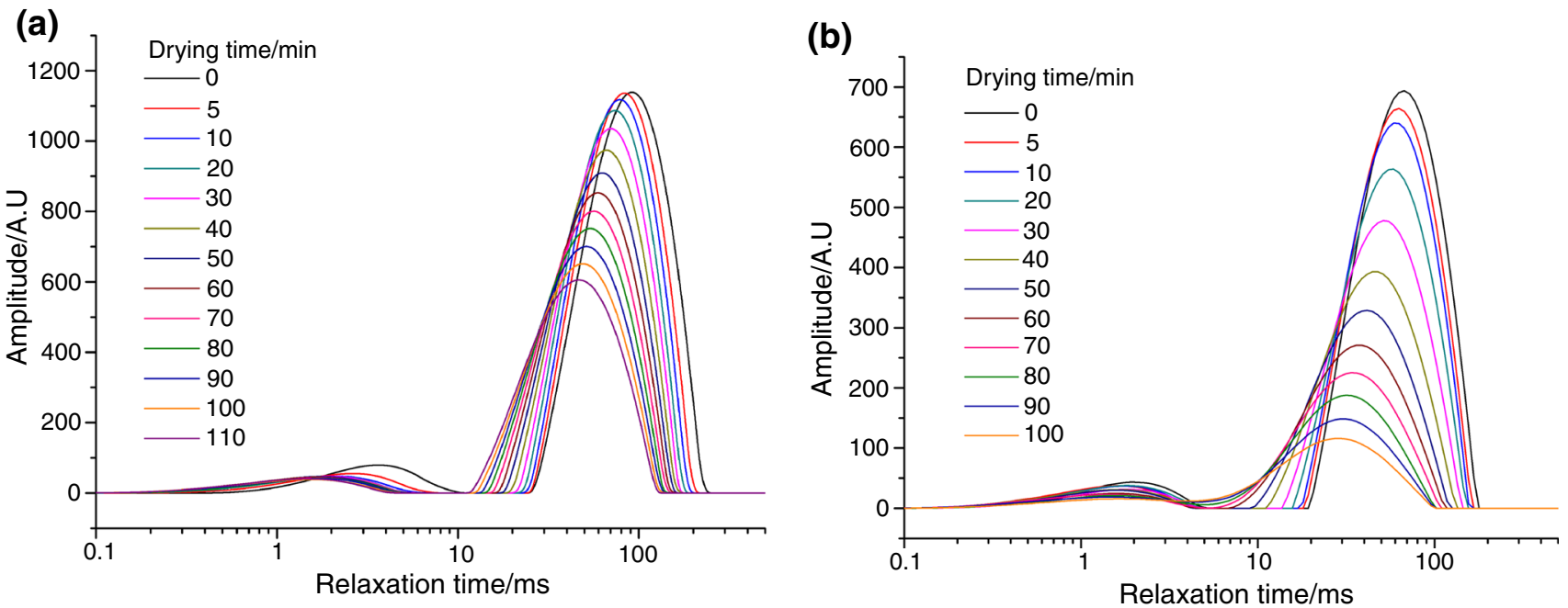

Fig. $6 T_{2}$ spectrum of FTL dried with different times under the $50{ }^{\circ} \mathrm{C}(\mathbf{a})$ and $60{ }^{\circ} \mathrm{C}(\mathbf{b})$

results of Table 2 that the moisture content of FTL was much higher than the dried tobacco leaves. Nevertheless, very little information is available in Fig. 5a, and only in the moisture content, not in the information of water activity. To gain more insight, we conducted signal inversion from drying time (Fig. 5a) to spin-spin relaxation time (Fig. 5b), which was completed by the CPMG sequence. In particular, there was a small relaxation peak between the $T_{21}$ peak and the $T_{22}$ peaks in the $T_{2}$ spectra of FTL with about $80 \%$ moisture content. However, as the moisture content of the tobacco leaves decreased during the drying process, the small peak gradually overlapped with the $T_{22}$ peak, and the intensity of the small peak could be almost negligible. Therefore, we could simply classify the moisture in tobacco leaves into bound water and semibound water. According to the water activity, the strength of relaxation peak of semi-bound water and bound water showed a great difference. The slow relaxation peak $\left(T_{22}\right.$ peak) of FTL in $T_{2}$ spectra was corresponding to the semibound water with high mobility. And the bound water with low mobility was corresponded to the fast relaxation peak ( $T_{21}$ peak).

The vaporization of moisture with polarized multilayers was a very complex process in fresh tobacco leaves, compared with pure water [9]. With the increment of water to macromolecules, additional layers of water link to monolayer in order to form the water multilayer. Either the attraction or the energy of water bonds is attenuated with the distance from macromolecules. $T_{2}$ can be used to indicate the mobility of these water layers, to identify each layer with different $T_{2}$ (strongly or weakly tied up according to water bond energy). In this work, the bound water and semi-bound water from the multilayer system presented a different $T_{2}$. In the fact, there were many other hydrogen bonding materials that could affect the $T_{2}$ of protons in the FTL. However, the content of these hydrogen bonding substances in tobacco leaves is, on the one hand, far below the moisture content. On the other hand, the drying process of fresh tobacco leaves under lowtemperature condition is dominated by the evaporation of moisture, while other hydrogen bonding materials with high boiling point were rarely volatized. Therefore, the relationship between moisture change and hydrogen bonding status in the drying process is mainly discussed in this work.

In order to study the water characteristics of FTL, the samples were measured under different drying conditions with the CPMG sequence. As shown in Fig. 6a, b, the $T_{22}$ peak in $T_{2}$ spectra gradually moved left during the drying process. The relaxation time of corresponding $T_{22}$ peak decreased from about $80 \mathrm{~ms}$ to about $45 \mathrm{~ms}$ at $50{ }^{\circ} \mathrm{C}$, and from about $80 \mathrm{~ms}$ to about $30 \mathrm{~ms}$ at $60{ }^{\circ} \mathrm{C}$, respectively. It indicated that water activity was weakened due to stronger bonding force between water molecules and the skeleton of tobacco materials. And it proved that the small relaxation peak between the $T_{21}$ peak and the $T_{22}$ peak gradually 
overlapped with the $T_{22}$ peak with the process of drying time. As the drying time progressed, the strength of the $T_{22}$ peak also decreased. It indicated that the proportion of semi-bound water in the tobacco leaves reduced constantly. With the increase in the hot air temperature, the absolute values of $T_{2}$ decreased at same drying time. Figure 7 plots the relaxation time of the $T_{22}$ peak as the function of the moisture ratio $(M R)$. Notably, the fitting results in Fig. 7 verified that the relaxation time of $T_{22}$ peak detected by

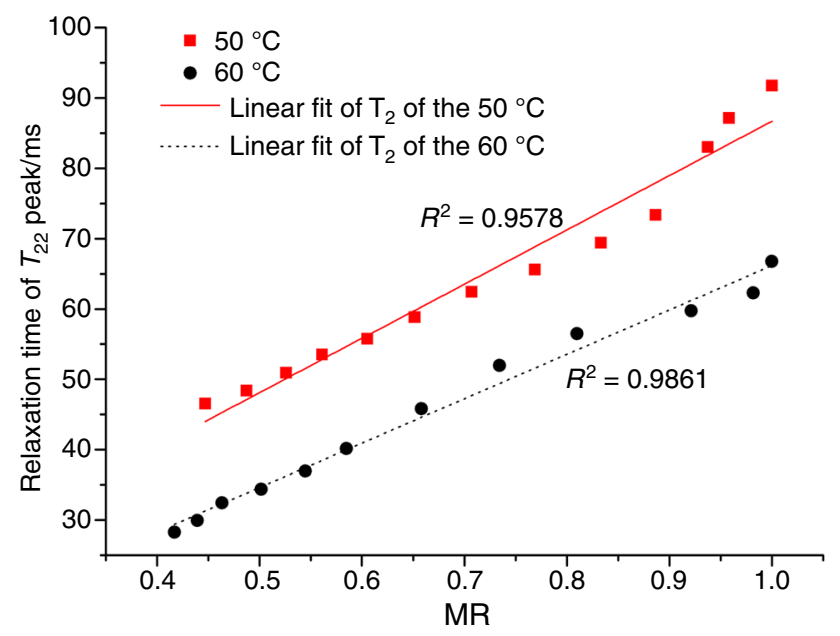

Fig. 7 Fitting results of moisture content and relaxation time of $T_{22}$ peak of FTL
NMR showed a great linear relationship (correlation coefficient $>0.95$ ) with the moisture ratio of tobacco leaves detected by TG during drying. These results demonstrated that the application of $T_{2}$ spectra in drying kinetics analysis is possible.

\section{Moisture distribution in FTL by MRI during drying}

The pseudo-color image was applied to visualize moisture distribution and migration within the tobacco materials during drying. As shown in Fig. 8, according to the concentration gradient displayed from magnetic resonance images, the drying process of FTL could be divided into two stages: Stage I and Stage II. As can be seen from Fig. 8a, the moisture distribution in materials showed the higher concentration gradient from the center to the side at the initial drying stage (Stage I). It showed that the water diffusion through cross section played a dominant role at initial stage. At the later drying stage (Stage II), the concentration gradient from the center to the side almost did not exist. It indicated that water in the materials diffused mainly through the top and the bottom surface. Furthermore, it should be pointed out that the area of magnetic resonance images decreased continuously owing to the shrinkage of tobacco leaves during drying process.
Fig. 8 Magnetic resonance images of FTL dried by different times under the $50{ }^{\circ} \mathrm{C}$ (a) and $60{ }^{\circ} \mathrm{C}(\mathbf{b})$

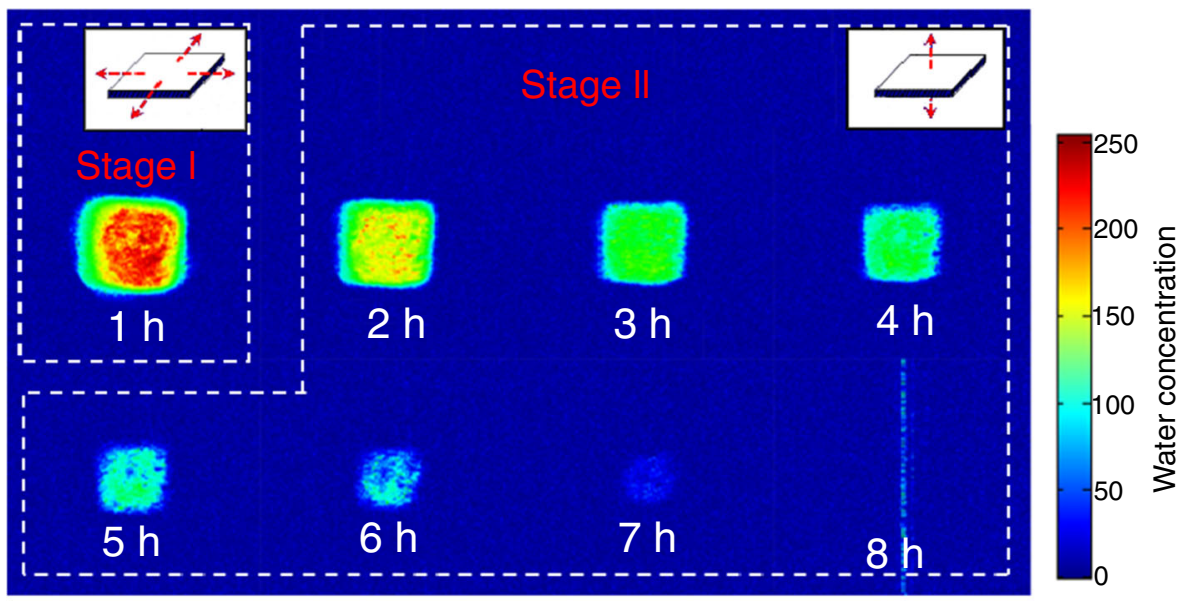

(a)

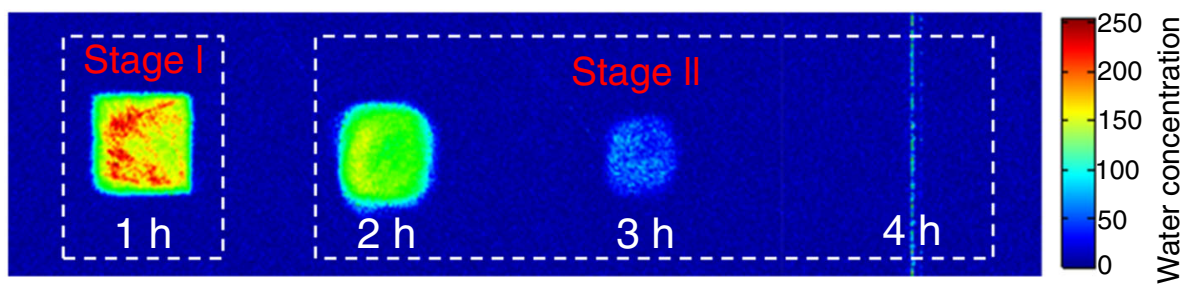

(b) 


\section{Conclusions}

On the basis of the drying rate results, it could be concluded that the drying process of FTL at 50 and $60{ }^{\circ} \mathrm{C}$ can be divided into two moisture loss stages. At mild drying condition $\left(50{ }^{\circ} \mathrm{C}\right)$, the drying process included the constant-rate stage and falling-rate stage. However, at more intense drying condition $\left(60^{\circ} \mathrm{C}\right)$, the constant-rate stage did not exist in the drying process, and the stage of sharp reduction in drying rate and stage of slow reduction in drying rate constituted the falling-rate loss stage.

The ratio of semi-bound water and bound water in FTL was 93.2 and $6.8 \%$, respectively, which could be calculated by relaxation peak strength in $T_{2}$ spectra. During the drying process, the strength of relaxation peak gradually reduced presumably due to the evaporation of semi-bound water at the beginning of the drying process, as it may be one of the reasons for the decreasing drying rate.

Moisture concentration gradient presented by MRI indicated that the moisture diffusion through cross section probably played a key role at the early drying stage. However, at the later drying stage, the concentration gradient from the center to the side did not exist almost, which indicated that the water had diffused mainly through top and bottom surface. This work could provide reference for better understanding the moisture transfer behavior in FTL during the fresh tobacco-curing process.

Acknowledgements Financial support from the National Natural Science Foundation of China (No. 51306213) and Key Lab of Tobacco Processing Technology of Zhengzhou Tobacco Research Institute (No. 212016AA0300) are gratefully acknowledged.

Open Access This article is distributed under the terms of the Creative Commons Attribution 4.0 International License (http://creative commons.org/licenses/by/4.0/), which permits unrestricted use, distribution, and reproduction in any medium, provided you give appropriate credit to the original author(s) and the source, provide a link to the Creative Commons license, and indicate if changes were made.

\section{References}

1. Nikolova V, Drachev D. Investigation influence on quality of different curing preparation of flue-cured tobacco. Biotechnol Biotechnol Equip. 2005;19(1):75-9.

2. Long M, Hua Y, Wang X, Wang Y, He C, Huangfu D, et al. Effect of different combined moistening and redrying treatments on the physicochemical and sensory capabilities of smoking food tobacco material. Drying Technol. 2018;36(1):52-62.

3. Zhu WK, Wang Y, Chen LY, Wang ZG, Li B, Wang B. Effect of two-stage dehydration on retention of characteristic flavor components of flue-cured tobacco in rotary dryer. Drying Technol. 2016;34(13):1621-9.

4. Wu J, Yang SX, Tian F. A novel intelligent control system for flue-curing barns based on real-time image features. Biosyst Eng. 2014;123:77-90.
5. W-k Z. Lin H, Cao Y, Li B. Thermal properties measurement of cut tobacco based on TPS method and thermal conductivity model. J Therm Anal Calorim. 2014;116(3):1117-23.

6. Li B, Zhu W, Wang P, Lu D, Wang L, Wang B. Fast drying of cut tobacco in drop tube reactor and its effect on petroleum ether tobacco extracts. Drying Technol. 2017;1-9. https://doi.org/10. 1080/07373937.2017.1402022.

7. Fernandes V, Araujo A, Fernandes G. TG study of the kinetic parameters of regeneration of coked HZSM-5 zeolite. J Therm Anal Calorim. 1999;56(2):811-7.

8. Cai X, Shen H, Zhang C, Wang Y, Kong Z. Application of constant reaction rate $\mathrm{TG}$ to the determination of kinetic parameters by Hi-Res TG. J Therm Anal Calorim. 2000;60(2):623-8.

9. Pitombo RN, Lima GA. Nuclear magnetic resonance and water activity in measuring the water mobility in Pintado (Pseudoplatystoma corruscans) fish. J Food Eng. 2003;58(1):59-66.

10. Sekiyama Y, Horigane AK, Ono H, Irie K, Maeda T, Yoshida M. $\mathrm{T}_{2}$ distribution of boiled dry spaghetti measured by MRI and its internal structure observed by fluorescence microscopy. Food Res Int. 2012;48(2):374-9.

11. Hills B. Applications of low-field NMR to food science. Annu Rep NMR Spectrosc. 2006;58:177-230.

12. Taghizadeh M, Gowen A, O'Donnell CP. Prediction of white button mushroom (Agaricus bisporus) moisture content using hyperspectral imaging. Sens Instrum Food Qual Saf. 2009;3(4):219.

13. Jin X, van Boxtel AJ, Gerkema E, Vergeldt FJ, Van As H, van Straten G, et al. Anomalies in moisture transport during broccoli drying monitored by MRI? Faraday Discuss. 2012;158(1):65-75.

14. Zhang L, McCarthy MJ. NMR study of hydration of navy bean during cooking. LWT Food Sci Technol. 2013;53(2):402-8.

15. Ruan R, Schmidt SJ, Schmidt AR, Litchfield JB. Nondestructive measurement of transient moisture profiles and the moisture diffusion coefficient in a potato during drying and absorption by NMR imaging. J Food Process Eng. 1991;14(4):297-313.

16. Ghosh PK, Jayas DS, Gruwel ML, White ND. A magnetic resonance imaging study of wheat drying kinetics. Biosyst Eng. 2007;97(2):189-99.

17. Bertram HC, Schäfer A, Rosenvold K, Andersen HJ. Physical changes of significance for early post mortem water distribution in porcine M. longissimus. Meat Sci. 2004;66(4):915-24.

18. Hong Y-S, Cho J-H, Kim N-R, Lee C, Cheong C, Hong KS, et al. Artifacts in the measurement of water distribution in soybeans using MR imaging. Food Chem. 2009;112(1):267-72.

19. Menon R, MacKay A, Hailey J, Bloom M, Burgess A, Swanson J. An NMR determination of the physiological water distribution in wood during drying. J Appl Polym Sci. 1987;33(4):1141-55.

20. $\mathrm{Xu} \mathrm{FF}$, Jin $X$, Zhang $L$, Chen XD. Investigation on water status and distribution in broccoli and the effects of drying on water status using NMR and MRI methods. Food Res Int. 2017;96:191-7.

21. Mateus M-L, Champion D, Liardon R, Voilley A. Characterization of water mobility in dry and wetted roasted coffee using lowfield proton nuclear magnetic resonance. J Food Eng. 2007;81(3):572-9.

22. Kuhn K, Kruschak W, Lechert H. Comparative NMR-investigations of the binding of water in starch and raw potatoes during the drying process. Starch-Staerke (Germany, FR); 1987.

23. Vicente J, Cappato LP, Calado VMDA, Carvalho MGD, GarciaRojas EE. Thermal and oxidative stability of Sacha Inchi oil and capsules formed with biopolymers analyzed by DSC and ${ }^{1} \mathrm{H}$ NMR. J Therm Anal Calorim. 2017;8:1-12.

24. Drábik M, Žurková L, Goljer I. Thermal reactivity and1H NMR spectroscopy of $\mathrm{Sr}_{1-\mathrm{x}} \mathrm{H}_{2 \mathrm{x}} \mathrm{V}_{6} \mathrm{O}_{16}$ aq. J Therm Anal Calorim. 1983;26(1):73-9. 
25. Pătraşcu F, Badea M, Grecu MN, Stanică N, Măruţescu L, Marinescu D, et al. Thermal, spectral, magnetic and antimicrobial behaviour of new $\mathrm{Ni}$ (II), $\mathrm{Cu}$ (II) and $\mathrm{Zn}$ (II) complexes with a hexaazamacrocyclic ligand. J Therm Anal Calorim. 2013;113(3):1421-9.

26. Barros N, Salgado J, Villanueva M, Rodriquez-Añón J, Proupin J, Feijóo S, et al. Application of DSC-TG and NMR to study the soil organic matter. J Therm Anal Calorim. 2010;104(1):53-60.

27. Faust M, Wang PC, Maas J. The use of magnetic resonance imaging in plant science. Horticult Rev. 1997;20:225-66.

28. Ruan R, Chang K, Chen PL, Fulcher RG, Bastian ED. A magnetic resonance imaging technique for quantitative mapping of moisture and fat in a cheese block. J Dairy Sci. 1998;81(1):9-15.

29. Horigane AK, Suzuki K, Yoshida M. Moisture distribution in rice grains used for sake brewing analyzed by magnetic resonance imaging. J Cereal Sci. 2014;60(1):193-201.

30. Shim JY, Tsushima S, Hirai S. High resolution MRI investigation of transversal water content distributions in PEM under fuel cell operation. In: Fuller T, Uchida H, Strasser P, Shirvanian P, Lamy $\mathrm{C}$, Hartnig $\mathrm{C}$, et al., editors. Proton exchange membrane fuel cells 9. ECS Transactions, vol. 1; 2009. p. 523-8.

31. Carr HW, Beckham HW, Spiess HW, Fulber C, Blumich B. Nuclear-magnetic-resonance imaging of water distributions in loop-pile nylon carpet tiles. J Text Inst. 1998;89(2):436-40.

32. Leisen J, Beckham HW. Quantitative magnetic resonance imaging of fluid distribution and movement in textiles. Text Res J. 2001;71(12):1033-45.
33. Oztop MH, Bansal H, Takhar P, McCarthy KL, McCarthy MJ. Using multi-slice-multi-echo images with NMR relaxometry to assess water and fat distribution in coated chicken nuggets. LWT Food Sci Technol. 2014;55(2):690-4.

34. Guillot G, Trokiner A, Darrasse L, Saint-Jalmes H. Drying of a porous rock monitored by NMR imaging. J Phys D Appl Phys. 1989;22(11):1646.

35. Carr HY, Purcell EM. Effects of diffusion on free precession in nuclear magnetic resonance experiments. Phys Rev. 1954;94(3):630.

36. Meiboom S, Gill D. Modified spin-echo method for measuring nuclear relaxation times. Rev Sci Instrum. 1958;29(8):688-91.

37. Le Botlan DJ, Ouguerram L. Spin-spin relaxation time determination of intermediate states in heterogeneous products from free induction decay NMR signals. Anal Chim Acta. 1997;349(1-3):339-47.

38. Jamradloedluk J, Nathakaranakule A, Soponronnarit S, Prachayawarakorn $\mathrm{S}$. Influences of drying medium and temperature on drying kinetics and quality attributes of durian chip. J Food Eng. 2007;78(1):198-205.

39. Panchariya P, Popovic D, Sharma A. Thin-layer modelling of black tea drying process. J Food Eng. 2002;52(4):349-57.

40. Crank J. The mathematics of diffusion. Oxford: Oxford University Press; 1979.

41. Mujumdar AS, Devahastin S. Fundamental principles of drying. Mujumdar's practical guide to industrial drying: equipment and new developments. Brossard: Exergex; 1979. p. 1-22. 